\section{Mandibular ameloblastoma treated by hemimandibulectomy and immediate free fibula flap reconstruction - a multidisciplinary approach: case report}

\author{
Marco Túllio Becheleni ${ }^{1}$, Felipe Eduardo Baires Campos ${ }^{1}$, Paulo Roberto da \\ Costa ${ }^{2}$, Roberto Junqueira Polizzi² ${ }^{2}$ Wagner Henriques de Castro ${ }^{1}$
}

\begin{abstract}
Ameloblastoma is a benign epithelial odontogenic tumor that presents locally invasive behavior associated with high recurrence rates. This case report aims to describe and illustrate the treatment of an extensive mandibular ameloblastoma. A 23-year-old male patient affected by ameloblastoma in the left jaw, complaining of edema in the region, dysphagia, and limitation of cervical movements. Presence of clinically visible ulcerated mass involving the teeth. Computed tomography showed an intraosseous, hypodense, expansive, multiloculated lesion. Left hemimandibulectomy was performed, followed by immediate free fibula flap reconstruction. Mandibular reconstruction with free flaps is an excellent modality to treat extensive multicystic ameloblastoma.
\end{abstract}

Keywords: ameloblastoma; mandibular diseases; mandibular reconstruction; odontogenic tumors; surgical flaps.

How to cite: Becheleni MT, Campos FEB, Costa PR, Polizzi RJ, Castro WH. Mandibular ameloblastoma treated by hemimandibulectomy and immediate free fibula flap reconstruction - a multidisciplinary approach: case report. Arch Head Neck Surg. 2021;50:e2021122. https://doi.org/10.4322/ahns.2020.0025

\section{Introduction}

Mandibular ameloblastoma (MA) is a benign odontogenic tumor of epithelial origin that presents locally invasive behavior and is often associated with high recurrence rates after surgical treatment ${ }^{1}$.

Both men and women are equally affected by MA, whose highest incidence occurs in the third and fourth decades of life. This neoplasm is usually discovered by the occurrence of asymptomatic swelling or in routine imaging tests. The mandible, mainly the region of the mandibular branch or associated with the crown of third molars, is the most common site of MAs².

The treatment of choice for conventional MA consists of surgery for resection of the lesion, including the removal of a portion of normal tissue, associated with the tumor, as a safety margin, as well as reconstruction of the bone defect resulting from the surgery using grafts or flaps. 


\section{Case report}

A 23-year-old Caucasian male patient sought the Department of Oral \& Maxillofacial Surgery, Hospital das Clínicas da Universidade Federal de Minas Gerais (HC-UFMG) complaining of a swelling with mild and spontaneous painful symptoms located in the left hemiface with a 6-year evolution history. The physical examination revealed a bulge in the region of the left mandibular body, restriction of the amplitude of mouth opening, and limitation to cervical motility. At oroscopy, ulcerations were observed on the mucosa that covered the swelling, probably associated with local trauma to the antagonistic teeth.

Cone beam computed tomography (CBCT) showed an intraosseous, hypodense, expansive, multiloculated, osteolytic image with the appearance of "soap bubbles" measuring $9.2 \times 3.6 \times 3.3 \mathrm{~cm}$ in their largest diameters (Figure 1). This change involved the entire posterior region of the mandible, on the left side, including the condylar process. Displacement of teeth (premolars and molars) was observed in the affected region and in the mandibular canal, in addition to resorption of dental roots.

An incisional biopsy of the lesion was performed considering the following diagnostic hypotheses: ameloblastoma, odontogenic myxoma, odontogenic keratocyst, ossifying fibroma, and central giant cell lesion. The results of the histopathological examination were compatible with the diagnosis of MA.

Treatment of the tumor consisted of segmental excision of the lesion with a safety margin. The resected mandibular segment extended from the distal margin of the lower left canine tooth to the ipsilateral mandibular condyle. At the same surgical time, reconstruction of the surgical defect was performed using a fibula osteomyocutaneous flap from the right lower limb (Figure 2). The fibula was formatted and fixed to the remaining mandibular bone using a $2.4 \mathrm{~mm}$ system reconstruction plate (Figure 3 ). The external carotid artery and the facial vein were anastomosed to the fibular artery and vein, respectively, for flap vascularization. The surgical wound was closed using primary suture, whereas the cutaneous portion of the flap was used to close the wound in its intraoral aspect. The postoperative length of hospital stay was 10 days.

After eight years of postoperative follow-up, with no signs of tumor recurrence, the patient received dental rehabilitation in the reconstructed region using an implant-supported prosthesis: three bone-integrated dental implants were installed in the fibular bone, enabling rehabilitation with ceramic dental prosthesis. The patient has been under longitudinal follow-up with no major complaints.

\section{Discussion}

According to the World Health Organization (WHO) is classified into ameloblastoma, unicystic ameloblastoma, and extraosseous/ peripheral ameloblastoma, and thus presents three clinical variants.

Scientific studies have indicated tumor resection with a safety margin as the treatment of choice for MAs. High recurrence rates (13-38\%) have been found when infiltrative MAs are treated conservatively 4 . 


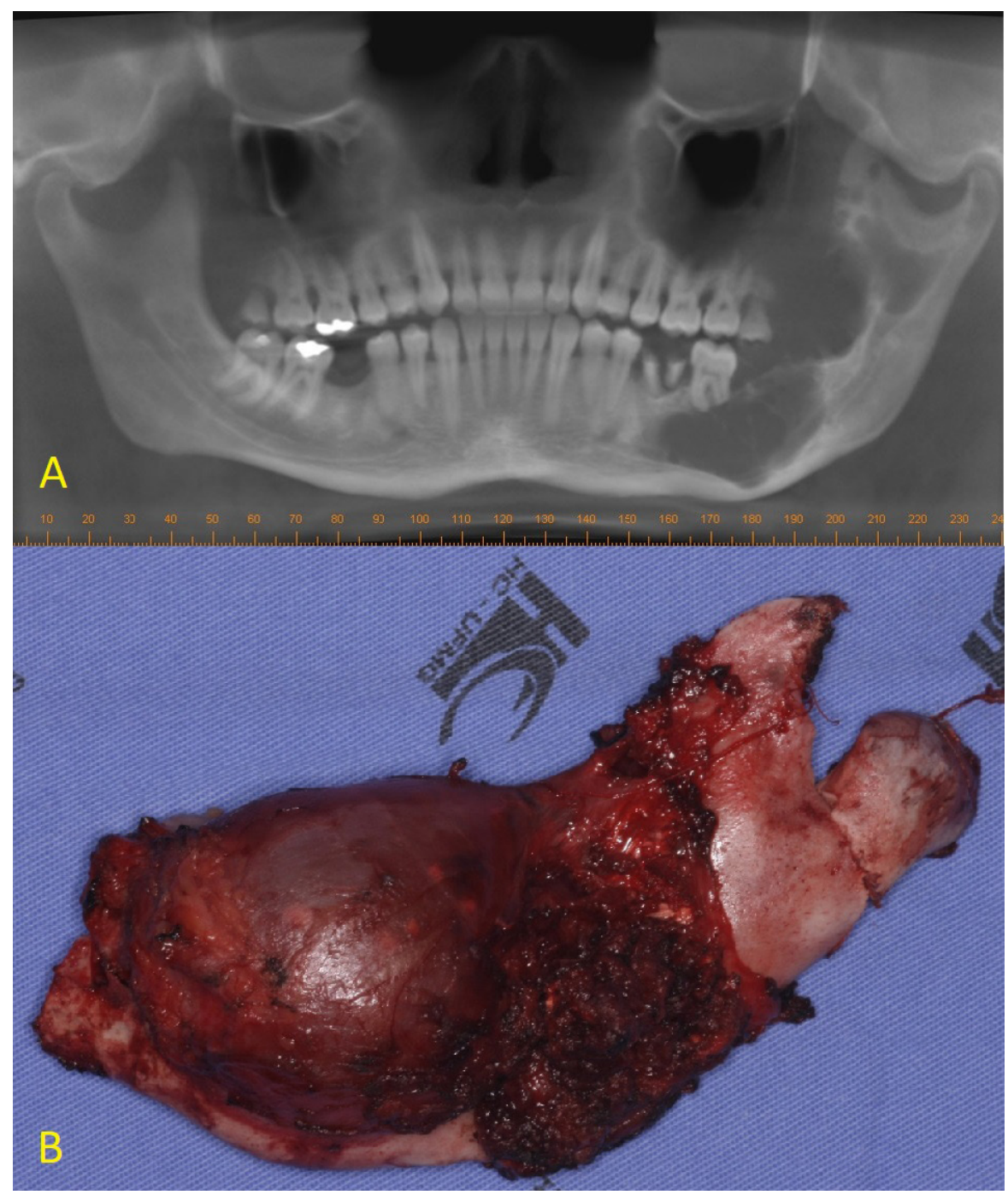

Figure 1. A - Cone beam computed tomography (CBCT) showing an intraosseous, hypodense, multiloculated lesion with the appearance of "soap bubbles"; B - Surgical specimen, showing extensive ameloblastoma affecting left mandibular segment.

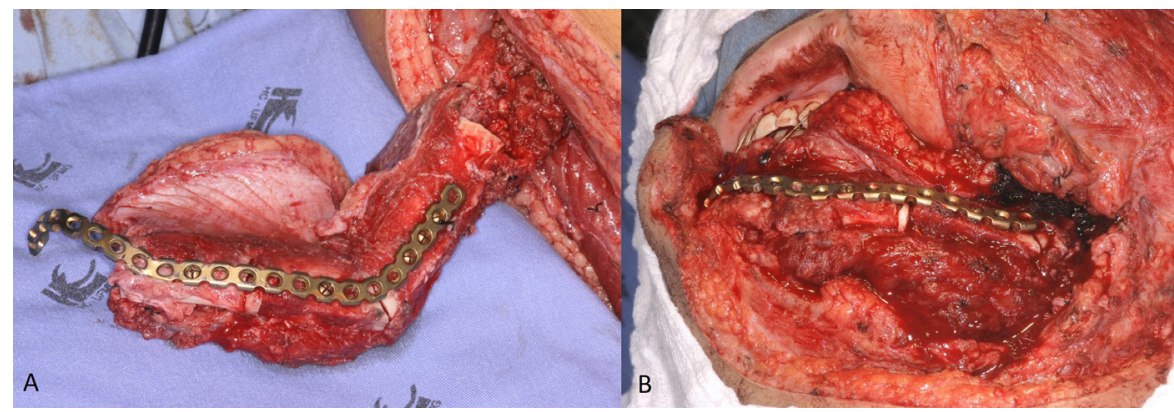

Figure 2. Transoperative photography showing: A - surgical access and evidence of the fibula flap being formed in the right lower limb; B - fibula flap positioned and fixed in the mandible using a $2.4 \mathrm{~mm}$ reconstruction plate, remaking the mandibular contour. 


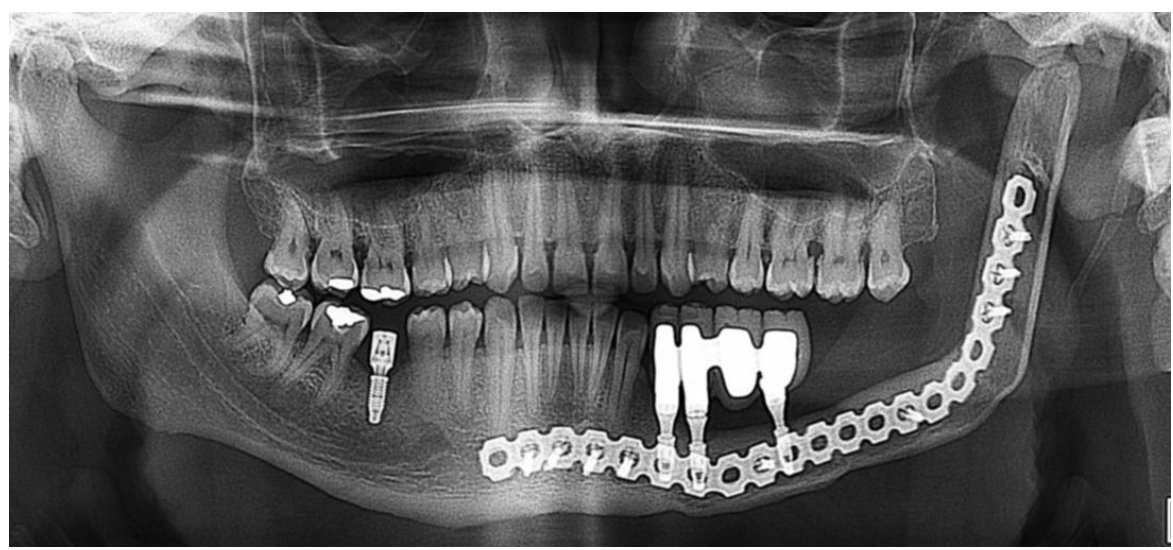

Figure 3. Panoramic radiography with an 8-year follow-up showing the flap in position, bone-integrated implants supporting dental prosthesis in the reconstructed region, good condition of the reconstruction plate, and absence of recurrences.

Microvascularized flaps in the maxillofacial region have been described as the "gold standard" for reconstruction of extensive bone defects after ablative tumor surgery ${ }^{5}$. Fibula flaps have indicated as an alternative that presents advantages over other donor sites, mainly due to the possibility of reconstructing large bone defects of up to $30 \mathrm{~cm}$, such as an entire mandibular arch. Flap perfusion through vascular anastomosis allows performance of multiple osteotomies with the aim of manipulating the flap into a shape similar to that of the mandible, thus preserving the patient's facial harmony. The possibility of using osseointegrated implants has also been cited in the literature as an advantage of this therapeutic management.

\section{Final remarks}

The best treatment for extensive mandibular ameloblastoma is resection of the tumor with a safety margin followed by immediate reconstruction of the bone defect using microvascularized fibula flaps. Construction of implantsupported prostheses on the bone component of the flap further accentuates the esthetic-functional results of the treatment.

\section{References}

1. Darshani Gunawardhana KS, Jayasooriya PR, Rambukewela IK, Tilakaratne WM. A clinico-pathological comparison between mandibular and maxillary ameloblastomas in Sri Lanka. J Oral Pathol Med. 2010;39(3):236-41. http:// dx.doi.org/10.1111/j.1600-0714.2009.00850.x. PMid:20070485.

2. Kalaskar R, Unawane AS, Kalaskar AR, Pandilwar P. Conservative management of unicystic ameloblastoma in a young child: report of two cases. Contemp Clin Dent. 2011;2(4):359-63. http://dx.doi.org/10.4103/0976-237X.91804. PMid:22346168.

3. Chan JKC, El-Naggar AK, Grandis JR, Takata T, Slootweg PJ. WHO classification of head and neck tumours. 4th ed. Geneva: WHO; 2017. 


\section{*Correspondence}

Marco Túllio Becheleni

Universidade Federal de Minas Gerais

(UFMG), Hospital das Clínicas, Serviço

de Cirurgia e Traumatologia Buco-

Maxilo-Facial

Av. Professor Alfredo Balena, 110,

Santa Efigênia

CEP 30130-000, Belo Horizonte (MG),

Brasil

E-mail: marco@cirurgiabmf.com

\section{Authors information}

MTB - Oral and Maxillofacial Surgeon, Hospital das Clínicas, UFMG; FEBC

- Ph.D. in Oral and Maxillofacial Surgery, Universidade Federal de Uberlândia; Professor, Department of Surgery, School of Dentistry, UFMG; Oral and Maxillofacial Surgeon, Hospital das Clínicas, UFMG. PRC - Ph.D. in Pathology, School of Medicine, Universidade Federal de Minas Gerais; Professor, Department of Plastic Surgery, School of Medicine, UFMG; Plastic Surgeon, Hospital das Clínicas, UFMG. RJP - Plastic Surgeon, Hospital das Clínicas, UFMG; WHC - Ph.D. in Pathology, School of Medicine, Universidade Federal de Minas Gerais; Professor, Department of Surgery, School of Dentistry, UFMG; Oral and Maxillofacial Surgeon, Hospital das Clínicas, UFMG.
4. Carvalho e Souza CH, Fé JLM, Sousa LLA, Borba MSDC, Barros SSLV, Lopes MCA. Radical management of aggressive lesions: a case report of recurrent ameloblastoma. RGO Rev Gaúch Odontol. 2015;63(3):327-30. http://dx.doi. org/10.1590/1981-863720150003000112674.

5. Oliveira BV, Ramos GHA, Pedruzzi PAG, Silva AB, Groth A, Sassi LM, Dissenha $J \mathrm{~L}$, Ribeiro R, Costa CN. Reconstrução da mandíbula utilizando o retalho microvascularizado de fíbula - 11 anos de experiência do Hospital Erasto Gaertner. Rev. Bras. Cir. Cabeça Pescoço. 2009;38(1):37-40. 